\title{
Retinoblastoma pM1b TNM Finding v7
}

National Cancer Institute

\section{Source}

National Cancer Institute. Retinoblastoma pM1b TNM Finding v7. NCI Thesaurus. Code C88746.

Multiple lesions. (from AJCC 7th Ed.) 